\title{
Editorial \\ A good laryngeal view does not guarantee perfectly successful tracheal intubation
}

\author{
Sung Mi Hwang \\ Department of Anesthesiology and Pain Medicine, Hallym University College of Medicine, Chuncheon, Korea
}

Difficult tracheal intubation is the most common factor related to serious airway complications during anesthesia [1]. Difficult tracheal intubation is defined as insertion of the endotracheal tube using direct laryngoscopy that requires more than two attempts lasting more than 10 min each or that requires an alternative technique [2]. The difficult airway involves interactions among patient factors, the clinical setting, and the practitioner's skills [3]. Many alternative tools and techniques have been developed to facilitate intubation in cases of difficult direct laryngoscopy. Among these, videolaryngoscopy (VL) improves glottis visualization using either an optical or video system, which allows communication between the operator and assistants and facilitates teaching; this method is gaining popularity [4]. Recently, VL has begun to be considered as a first-line tool for airway management, rather than as a rescue tool for difficult intubation $[3,5,6]$. However, VL does not achieve a $100 \%$ intubation success rate, and complications have been associated with the procedure $[5,7,8]$. With VL, the success of intubation lies not in the view obtained, but in the ease of inserting the endotracheal tube. Instead of the Cormack-Lehane scoring system, Swann et al. [9] proposed the Fremantle score, calculated using a threepart scoring system based on the laryngeal view (full, partial, or no view), ease of endotracheal intubation (easy, modified, or unachievable), and device used. The Korean Society of Anesthesiologists should consider the use of this new scoring system and various tools for cases of difficult intubation.

Corresponding author: Sung Mi Hwang, M.D., Ph.D.

Department of Anesthesiology and Pain Medicine, Chuncheon Sacred Heart Hospital, 77 Sakju-ro, Chuncheon 24253, Korea

Tel: 82-33-240-5155, Fax: 82-33-251-0941

E-mail: h70sm@hallym.or.kr

ORCID: http://orcid.org/0000-0002-3141-544X

Korean J Anesthesiol 2016 April 69(2): 111-112 http://dx.doi.org/10.4097/kjae.2016.69.2.111
In this issue of the Korean Journal of Anesthesiology, Shim et al. [10] compared GlideScope ${ }^{\circledR}$ and McGrath ${ }^{\circledR}$ laryngoscopes in simulated cases of difficult intubation. They used a four-grade videoscopic view. However, they did not precisely describe the grade. In addition, a tube exchanger and vascular forceps were used instead of a rigid stylet, which can be associated with complications [8]. Although a difficult airway was simulated with an extrication collar, actual patients with difficult airways were excluded. In the simulation, the first-attempt success rates were 82.8\% (GlideScope ${ }^{\circledR}$ group) and $83.8 \%$ (McGrath ${ }^{\circledR}$ group).

Failed intubation with the GlideScope ${ }^{\circledR}$ was also reported in this issue of the Korean Journal of Anesthesiology [11]. There was resistance to passage of the endotracheal tube into the larynx with a conventional laryngoscope. The GlideScope ${ }^{\circledR}$ then revealed that a septum divided the subglottic area into two sections. A laryngeal mask did not provide adequate ventilation due to laryngeal edema caused by multiple intubation attempts, and the surgery was postponed. In this case, the patient failed to recall any previous difficulties with anesthesia. The preanesthetic history, chest radiography, and spirometry failed to reveal the patient's tracheal stenosis under the vocal cords. The difficulty grade of direct laryngoscopy was not described; passing the endotracheal tube was impossible due to the unusual trachea. A full view of the larynx was obtained using direct laryngoscopy and the GlideScope ${ }^{\circledR}$.

Considering these two articles, we need to keep in mind that neither the use of VL nor achievement of a laryngeal view guarantees intubation success. Accurately predicting a difficult airway remains as a cornerstone of airway management. Furthermore, considering the recognized associations between a difficult airway and patient characteristics, the patient's medical history may help to predict a difficult airway $[3,12]$. To avoid airway complications, anesthesiologists should be proficient in the use of a wide range of anesthetic airway techniques and alternative intubation tools and should know how to manage

(c) This is an open-access article distributed under the terms of the Creative Commons Attribution Non-Commercial License (http://creativecommons.org/ licenses/by-nc/4.0/), which permits unrestricted non-commercial use, distribution, and reproduction in any medium, provided the original work is properly cited. 
a failed airway, including when and how they will wake the patient in cases of difficulty [1]. In addition, for follow-up care, the anesthesiologist should inform the patient of the airway difficulty that was encountered. A written report that describes the difficult airway, including the apparent reasons for difficulty, how the intubation was finally accomplished, and the implica- tions for future care, is recommended [3].

In conclusion, anesthesiologists should determine a strategy for a difficult intubation. They should assemble a team that can assist one another and make prompt decisions, use the most familiar and skilled tool, and record the findings in detail.

\section{References}

1. Cook TM, MacDougall-Davis SR. Complications and failure of airway management. Br J Anaesth 2012; 109 Suppl 1: i68-85.

2. Langeron O, Cuvillon P, Ibanez-Esteve C, Lenfant F, Riou B, Le Manach Y. Prediction of difficult tracheal intubation: time for a paradigm change. Anesthesiology 2012; 117: 1223-33.

3. Apfelbaum JL, Hagberg CA, Caplan RA, Blitt CD, Connis RT, Nickinovich DG, et al. Practice guidelines for management of the difficult airway: an updated report by the American Society of Anesthesiologists Task Force on management of the difficult Airway. Anesthesiology 2013; 118: 251-70.

4. Savoldelli GL, Schiffer E, Abegg C, Baeriswyl V, Clergue F, Waeber JL. Comparison of the GlideScope ${ }^{\circledR}$, $\operatorname{the~McGrath~}^{\circledR}$, $\operatorname{the}^{\text {Airtraq }}{ }^{\circledR}$ and the Macintosh laryngoscopes in simulated difficult airways. Anaesthesia 2008; 63: 1358-64.

5. Rothfield KP, Russo SG. Videolaryngoscopy: should it replace direct laryngoscopy? a pro-con debate. J Clin Anesth 2012; 24: 593-7.

6. Paolini JB, Donati F, Drolet P. Review article: video-laryngoscopy: another tool for difficult intubation or a new paradigm in airway management? Can J Anaesth 2013; 60: 184-91.

7. Cooper RM. Complications associated with the use of the GlideScope videolaryngoscope. Can J Anaesth 2007; 54: 54-7.

8. Leong WL, Lim Y, Sia AT. Palatopharyngeal wall perforation during GlideScope intubation. Anaesth Intensive Care 2008; 36: 870-4.

9. Swann AD, English JD, O'Loughlin EJ. The development and preliminary evaluation of a proposed new scoring system for videolaryngoscopy. Anaesth Intensive Care 2012; 40: 697-701.

10. Shim JH, Jeon WJ, Cho SY, Choe GH. Comparison of the GlideScope and the McGrath method using vascular forceps and a tube exchanger in cases of simulated difficult airway intubation. Korean J Anesthesiol 2016; 69: 133-7.

11. Youn AM, Yoon SH, Park SY. Failed intubation of an unanticipated postintubation tracheal stenosis. Korean J Anesthesiol 2016; 69: 167-70.

12. Neyrinck A. Management of the anticipated and unanticipated difficult airway in anesthesia outside the operating room. Curr Opin Anaesthesiol 2013; 26: 481-8. 